\title{
Metamorphosis and inshore migration of tropical eels Anguilla spp. in the Indo-Pacific
}

\author{
Takaomi Arai $^{1, *}$, Daniel Limbong ${ }^{2}$, Tsuguo Otake ${ }^{3}$, Katsumi Tsukamoto ${ }^{1}$ \\ ${ }^{1}$ Ocean Research Institute, The University of Tokyo, Minamidai, Nakano, Tokyo 164-8639, Japan \\ ${ }^{2}$ Faculty of Fisheries and Marine Science, Sam Ratulangi University, Manado 95115, Indonesia \\ ${ }^{3}$ Faculty of Bioresources, Mie University, Kamihama, Tsu 514-8507, Japan
}

\begin{abstract}
In order to determine the early life history and recruitment mechanisms of tropical eels Anguilla spp. in the Indo-Pacific, the timing of metamorphosis and age at recruitment to freshwater habitats were established from otolith microstructure and microchemistry analyses of juveniles of Anguilla celebesensis, A. marmorata and A. bicolor bicolor. Otolith increment width markedly increased from the age of $124 \pm 12.0 \mathrm{~d}$ (mean $\pm \mathrm{SD}$ ) in $A$. celebesensis, $120 \pm 13.0 \mathrm{~d}$ in $\mathrm{A}$. marmorata (Philippines), $120 \pm 15.6 \mathrm{~d}$ in A. marmorata (Indonesia) and $139 \pm 15.9 \mathrm{~d}$ in A. bicolor bicolor. The timing of these increases was coincident with drastic decreases in otolith Sr:Ca ratios in each species, indicating the onset of metamorphosis from leptocephalus to glass eel. The mean duration of metamorphosis was 17 to $18 \mathrm{~d}$ in each species. Age at recruitment (mean $\pm \mathrm{SD}$ ) was $157 \pm 13.7 \mathrm{~d}$ in $\mathrm{A}$. celebesensis, $154 \pm 13.5 \mathrm{~d}$ in $A$. marmorata (Philippines), $152 \pm 15.2 \mathrm{~d}$ in A. marmorata (Indonesia) and $177 \pm 16.4 \mathrm{~d}$ in $A$. bicolor bicolor. In all species examined, close linear relationships were found between ages at metamorphosis and recruitment, suggesting that individuals which metamorphosed earlier were recruited to freshwater habitats at a younger age.
\end{abstract}

KEY WORDS: Eel · Tropical Anguilla spp. Otolith · Growth increments · Sr:Ca ratios · Metamorphosis Long larval phase

\section{INTRODUCTION}

The freshwater eels of the genus Anguilla, being catadromous, migrate between freshwater growth habitats and offshore spawning areas. Among various life history events in Anguilla spp., metamorphosis from leptocephalus to glass eel is one of the more interesting phenomena. The timing of metamorphosis or the lengthy duration of the leptocephalus stage, seems to be an important biological key for determining the geographical distribution of the eel (Tsukamoto \& Umezawa 1994). Long-term larval migration in the sea might be involved in the worldwide distribution of the genus and consequent speciation of Anguilla species (Tsukamoto 1994, Tsukamoto \& Aoyama 1998). Worldwide, 18 species/subspecies of Anguilla have been reported (Ege 1939, Matsui 1972, Castle \&

·E-mail: arait@ori.u-tokyo.ac.jp
Williamson 1974), 12 being known in tropical regions. Of the latter, 7 species/subspecies occur in the western Pacific around Indonesia, i.e. A. celebesensis, A. interioris, A. nebulosa nebulosa, A. marmorata, A. borneensis, A. bicolor bicolor and A. bicolor pacifica (Ege 1939, Matsui 1972, Castle \& Williamson 1974). Recent mitochondrial DNA analysis revealed that $A$. borneensis from Borneo Island was closest to the ancestral form among the 18 present-day species/subspecies. Accordingly, freshwater eels have been suggested as having originated in the present-day Indonesian region during the Cretaceous (Aoyama 1998). Furthermore, the tropical species seem to be more closely related to the ancestral form than their temperate counterparts. Thus, studying larval migration and metamorphosis in tropical eels may provide some clues to understanding what is a primitive form of catadromous migration in freshwater eels and how large-scale migration of temperate species was established. 
Recent progress in otolith analytical techniques have revealed considerable details of early life history, including the timing and duration of metamorphosis of temperate Anguilla species, such as A. japonica, $A$. anguilla and $A$. rostrata. There have also been many reports describing otolith microstructure and growth patterns (Tabeta et al. 1987. Tsukamoto 1990, Tzeng 1990, Tsukamoto \& Umezawa 1990, Umezawa \& Tsukamoto 1990, Lecomte-Finiger 1992, Tzeng \& Tsai 1992, Cheng \& Tzeng 1996, Wang \& Tzeng 1998, Arai et al. 1999), and patterns of Sr:Ca ratios (Otake et al. 1994, Tzeng 1994, Tzeng \& Tsai 1994, Tzeng 1996, Arai et al. 1997). We validated the timing of metamorphosis in A. japonica by examining both otolith microstructure and microchemistry of fully-grown leptocephali (just before metamorphosis) and glass eels. A marked increase in otolith increment width, coincident with a drop in Sr:Ca ratio was found to herald the onset of metamorphosis (Arai et al. 1997). The latter appeared to be completed before the maximum peak of otolith increment width. However, such information has been obtained mainly from temperate species and little is known about the early life history of tropical species, including aspects such as spawning area and season, larval growth and metamorphosis, migration and even recruitment of juveniles to estuarine habitats.

In the present study, we examined otolith microstructure and microchemistry of the tropical species, Anguilla bicolor bicolor McClelland, A. celebesensis Kaup and A. marmorata Quoy \& Gaimard, collected from tropical regions of the Indo-Pacific, and deter- mined the timing and duration of metamorphosis, age at recruitment and hatching date. The results formed the basis of a discussion on the larval migration mechanisms in these species.

\section{MATERIALS AND METHODS}

Fish and otolith preparation. Juveniles of Anguilla celebesensis and $A$. marmorata were collected with a scoop net at the mouth of the Cagayan River, Philippines, on September 24, 1994 (Fig. 1). The juveniles sampled were kept in freshwater for $10 \mathrm{~d}$, transported to Japan and thereafter frozen. Juveniles of A. marmorata were collected with a dip net at the mouth of the Dumoga River, North Sulawesi Island, Indonesia, on June 5, 1996. Juveniles of A. bicolor bicolor were collected with a scoop net at the mouth of the Cimandiri River, Java Island, Indonesia, on May 30, 1996. Juveniles of the latter 2 species were preserved in $99 \%$ ethanol immediately after sampling. A total of 65 specimens $(17 \mathrm{~A}$. celebesensis, $13 \mathrm{~A}$. marmorata from the Philippines, $20 \mathrm{~A}$. marmorata from Indonesia and $15 \mathrm{~A}$. bicolor bicolor) was used for the present study (Table 1). Total length (TL), external morphology, and predorsal, ano-dorsal and preanal length of the specimens were measured to the nearest $0.1 \mathrm{~mm}$. The pigmentation stage was also examined, following Bertin (1956). After otolith extraction, all of the specimens were refixed (in $10 \%$ formalin), stained with alizarin, and predorsal, ano-dorsal, preanal and total vertebrae counted. All

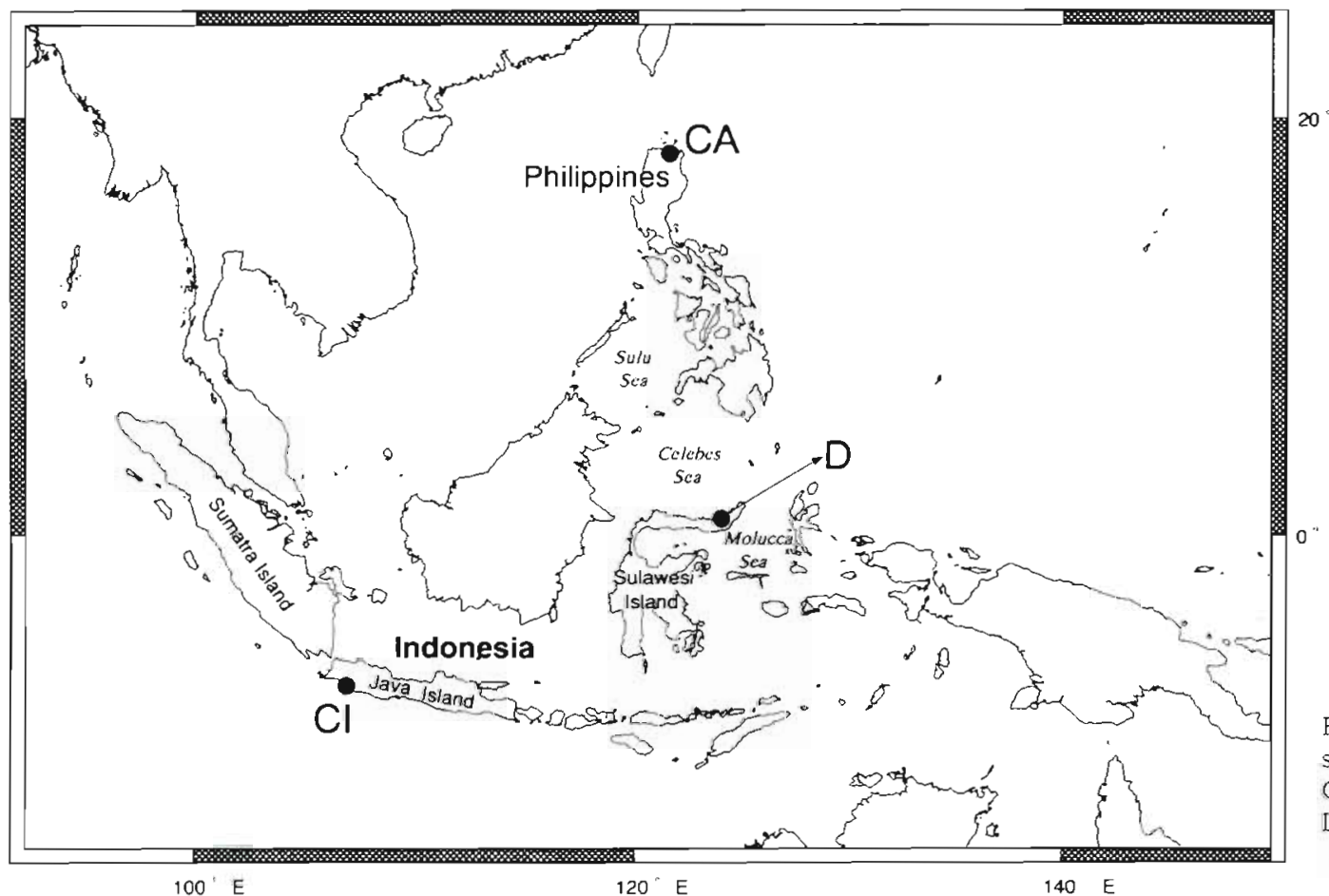

Fig. 1 Map showing sampling locations ( CI: Cimandiri River: D: Dumoga River; and CA: Cagayan River 
Table 1. Tropical Anguilla spp. TL: total length; OR: otolith radius; DL: duration of leptocephalus stage; DM: duration of metamorphosis stage; AR: age at recruitment; and HD: hatching date (Mean \pm SD, range) of juveniles

\begin{tabular}{|c|c|c|c|c|}
\hline Sampling location: & $\begin{array}{c}\text { A. celebesensis } \\
\text { Cagayan River, } \\
\text { Philippines }\end{array}$ & $\begin{array}{c}\text { A. marmorata } \\
\text { Cagayan River, } \\
\text { Philippines }\end{array}$ & $\begin{array}{l}\text { A. marmorata } \\
\text { Dumoga River, } \\
\text { Indonesia }\end{array}$ & $\begin{array}{l}\text { A. bicolor bicolor } \\
\text { Cimandiri River, } \\
\text { Indonesia }\end{array}$ \\
\hline $\begin{array}{l}\text { No. of specimens } \\
\text { examined }\end{array}$ & 17 & 13 & 20 & 15 \\
\hline $\begin{array}{l}\text { No. of specimens } \\
\text { age determined }\end{array}$ & 13 & 10 & 18 & 12 \\
\hline $\mathrm{TL}(\mathrm{mm})$ & $51.2 \pm 1.7,48.4$ to 54.6 & $49.9 \pm 1.4,47.2$ to 51.6 & $50.9 \pm 2.0,47.9$ to 54.8 & $49.4 \pm 2.4,45.5$ to 52.3 \\
\hline $\mathrm{OR}(\mu \mathrm{m})$ & $163 \pm 7.4,156$ to 182 & $160 \pm 10.2,144$ to 174 & $146 \pm 5.3,134$ to 156 & $164 \pm 6.3,155$ to 176 \\
\hline $\mathrm{DL}$ (d) & $124 \pm 12.0,104$ to 147 & $120 \pm 13.0,105$ to 140 & $120 \pm 15.6,96$ to 147 & $139 \pm 15.9,119$ to 171 \\
\hline $\operatorname{DM}(\mathrm{d})$ & $17 \pm 3.2,12$ to 24 & $17 \pm 4.3,13$ to 26 & $17 \pm 3.3,13$ to 24 & $18 \pm 4.2,13$ to 27 \\
\hline $\mathrm{AR}(\mathrm{d})$ & $157 \pm 13.7,130$ to 177 & $154 \pm 13.5,136$ to 178 & $152 \pm 15.2,129$ to 177 & $177 \pm 16.4,148$ to 202 \\
\hline $\mathrm{HD}$ & $\begin{array}{c}\text { Apr } 201994 \pm 13.7 \\
\text { Mar } 311994 \text { to } \\
\text { May } 171994\end{array}$ & $\begin{array}{c}\text { Apr } 231994 \pm 13.5 \\
\text { Mar } 301994 \text { to } \\
\text { May } 111994\end{array}$ & $\begin{array}{c}\text { Jan } 41996 \pm 15.2 \\
\text { Dec } 111995 \text { to } \\
\text { Jan } 281996\end{array}$ & $\begin{array}{c}\text { Dec } 51995 \pm 16.4 \\
\text { Nov } 101995 \text { to } \\
\text { Jan } 31996\end{array}$ \\
\hline
\end{tabular}

specimens were identified from their external morphology and sectional vertebral counts according to Ege (1939) and Tabeta et al. (1976).

Sagittal otoliths were extracted from each fish, embedded in epoxy resin (Struers, Epofix) after measurement of the radius and mounted on glass slides. The otoliths were then ground to expose the core using a grinding machine equipped with a diamond cup-wheel (Struers, Discoplan-TS), and further polished with $6 \mu \mathrm{m}$ and $1 \mu \mathrm{m}$ diamond paste on an automated polishing wheel (Struers, Planopol-V). Finally, they were cleaned in an ultrasonic bath and rinsed with deionized water, prior to examinations.

Otolith $\mathbf{x}$-ray microprobe analysis. For electron microprobe analyses, 30 otoliths (5 Anguilla celebesensis, $5 \mathrm{~A}$. marmorata from the Philippines, $10 \mathrm{~A}$. marmorata from Indonesia and $10 \mathrm{~A}$. bicolor bicolor) were carbon coated by high vacuum evaporator. $\mathrm{Sr}$ and $\mathrm{Ca}$ concentrations were measured along the longest axis of each otolith using a wavelength dispersive $x$-ray electron microprobe (JEOL JXA-733), as described in Arai et al. (1997, 1999) and Arai \& Tsukamoto (1998). Accelerating voltage and beam current were $15 \mathrm{kV}$ and $7 \mathrm{nA}$, respectively. The electron beam was focused on a point approximately $1 \mu \mathrm{m}$ in diameter, with intervals of $1 \mu \mathrm{m}$ between spacing measurements. Each datum represents the average of 3 measurements (each counting time: 4.0 s). Microprobe measurement points, which were seen as burn depressions (Fig. 2A), were assigned to otolith growth increments, which were examined as described below. Averages of $\mathrm{Sr}$ and $\mathrm{Ca}$ concentration data, pooled after every 10 successive growth increments, were used for the life-history transect analyses.

Otolith increment analysis. Following electron microprobe analysis, the otoliths were repolished to remove the coating, etched with $0.05 \mathrm{M} \mathrm{HCl}$ and vacuum coated with Pt-Pd in an ion-sputterer for scanning elec-

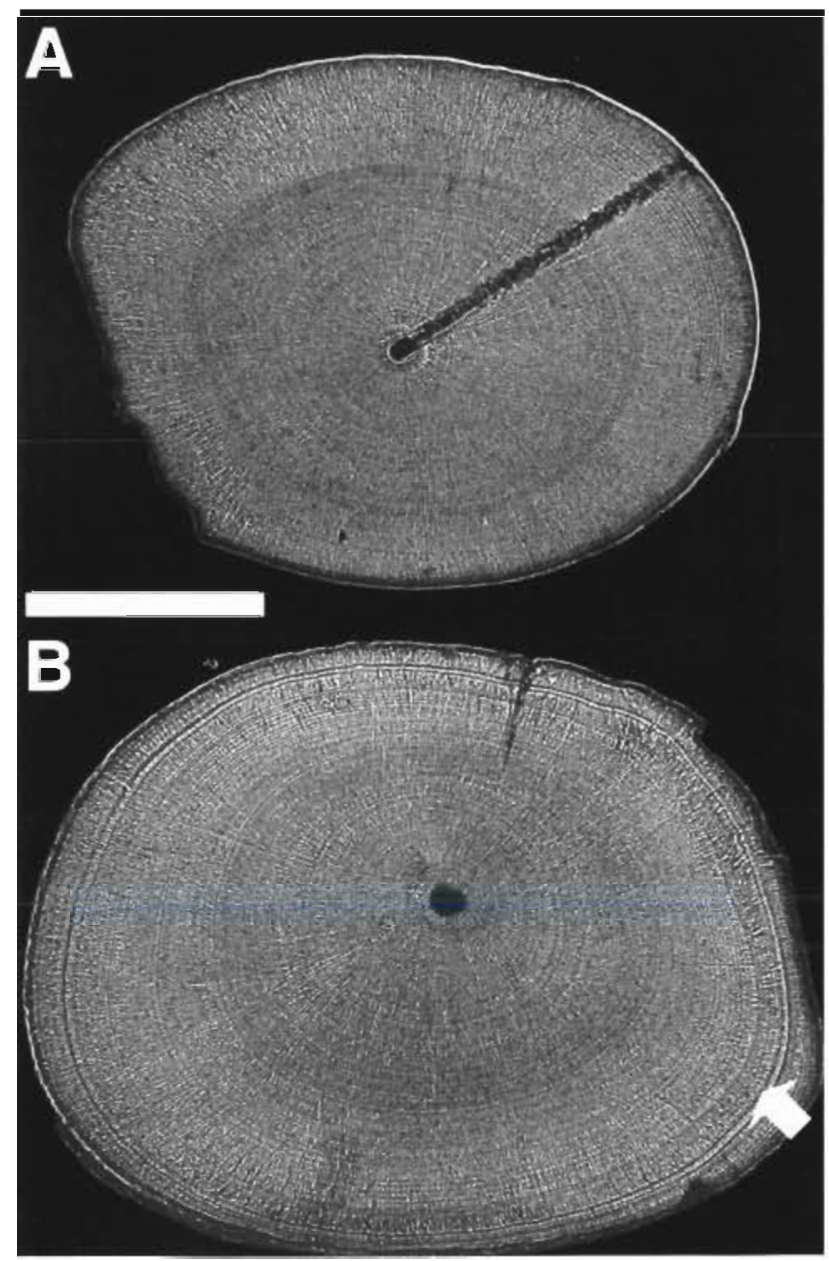

Fig. 2. Anguilla celebesensis and A. marmorata. SEM photographs showing microstructure of etched otolith. (A) A. marmorata glass eel (TL $47.9 \mathrm{~mm}$ ) collected at mouth of Dumoga River. (B) A. celebesensis elver (TL $54.6 \mathrm{~mm}$ ) collected at mouth of Cagayan River. (Arrow) distinct check. Scale bar: $100 \mu \mathrm{m}$ 
tron microscope (SEM, Hitachi S-4500) observations The ground surfaces of otoliths of 35 specimens (12 Anguilla celebesensis, $8 \mathrm{~A}$. marmorata from the Philippines, $10 \mathrm{~A}$. marmorata from Indonesia and $5 \mathrm{~A}$. bicolor bicolor), which were not used for electron microprobe analysis, were also etched and coated using the above procedure for SEM observation. SEM photographs at various magnifications $(150,180,1000$, and $1500 \times)$ were used for counting the number of growth increments and measuring their widths. The 'radius', from the core to the edge along the longest axis of the ground otolith surface, was regarded as the otolith radius along which increment widths were measured. The averages of every 10 successive ring widths between the hatch check (Umezawa et al. 1989) (about $10 \mu \mathrm{m}$ in diameter) and the edge or check (see 'Results': Otolith microstructure) were used for the otolith growth analyses. Since Umezawa et al. (1989), Tsukamoto (1989) and Umezawa \& Tsukamoto (1991) showed clearly that otolith increments in A. japonica were deposited daily, we considered the number of increments to represent the daily age of each specimen, although daily deposition had not been validated in these species.

Statistical analyses. Differences among data were tested by an analysis of variance (ANOVA) and afterwards Scheffe's multiple range test for the combination of 2 data. Significance of the correlation coefficient and regression slope were tested by Fisher's Z-transformation and an analysis of covariance (ANCOVA), respectively (Sokal \& Rohlf 1969).

\section{RESULTS}

\section{Size and pigmentation at recruitment}

The TLs of juvenile Anguilla celebesensis and $A$. marmorata from the Philippines were $51.2 \pm 1.7 \mathrm{~mm}$ (mean $\pm \mathrm{SD}$ ) and $49.9 \pm 1.4 \mathrm{~mm}$, respectively, and those of $A$. marmorata from Indonesia and $A$. bicolor bicolor $50.9 \pm 2.0 \mathrm{~mm}$ and $49.4 \pm 2.4 \mathrm{~mm}$, respectively (Table 1 ) Although a significant difference in TL occurred between $A$. marmorata from Indonesia and $A$. bicolor bicolor (ANOVA, $\mathrm{p}<0.05$ ), a combination between $A$. celebesensis and A. marmorata from the Philippines was not significant.

The pigmentation in both Anguilla marmorata from Indonesia and $A$. bicolor bicolor was scarcely developed, being only on the caudal or skull, caudal and rostral regions of the body and was thus apparently classified at the glass eel stage (VA or VB). Pigmentation in juvenile $A$. celebesensis and $A$. marmorata from the Philippines was advanced along the entire dorsal region of the body, resulting in classification as stage VIA ${ }_{I I}$ or VIA IV, i.e. elvers.

\section{Otolith microstructure}

The mean radii of otoliths of Anguilla celebesensis and A. marmorata from the Philippines were 163 $( \pm 7.4 \mathrm{SD}) \mu \mathrm{m}$ and $160( \pm 10.2 \mathrm{SD}) \mu \mathrm{m}$, respectively. Those of $A$. marmorata and $A$. bicolor bicolor from Indonesia were $146( \pm 5.3 \mathrm{SD}) \mu \mathrm{m}$ and $164( \pm 6.3 \mathrm{SD}) \mu \mathrm{m}$, respectively (Table 1). A highly significant difference in otolith radius was obtained between $A$. marmorata from Indonesia and $A$. bicolor bicolor at the same developmental stage (ANOVA, $p<0.0001$ ), while $A$. celebesensis and $A$. marmorata from the Philippines did not differ significantly. An otolith core was observed as a deep hole in each etched otolith, a hatch check being visible as a deep circular groove surrounding the hole (Fig. 3). The diameter of the hatch check was $10.4 \pm 0.9 \mu \mathrm{m}$ (mean $\pm \mathrm{SD}$ ) in A. celebesensis, $9.8 \pm 0.8 \mu \mathrm{m}$ (mean $\pm \mathrm{SD}$ ) in A. marmorata from the Philippines, $9.6 \pm 1.1 \mu \mathrm{m}$ (mean $\pm \mathrm{SD}$ ) in $A$. marmorata from Indonesia and $9.9 \pm 0.9 \mu \mathrm{m}$ (mean $\pm \mathrm{SD}$ ) in $A$. bicolor bicolor. A significant difference occurred between $A$. celebesensis and A. marmorata from Indonesia (ANOVA, $p<0.05$ ), but other combinations were not significant. Distinct concentric growth increments, comprising a series, were

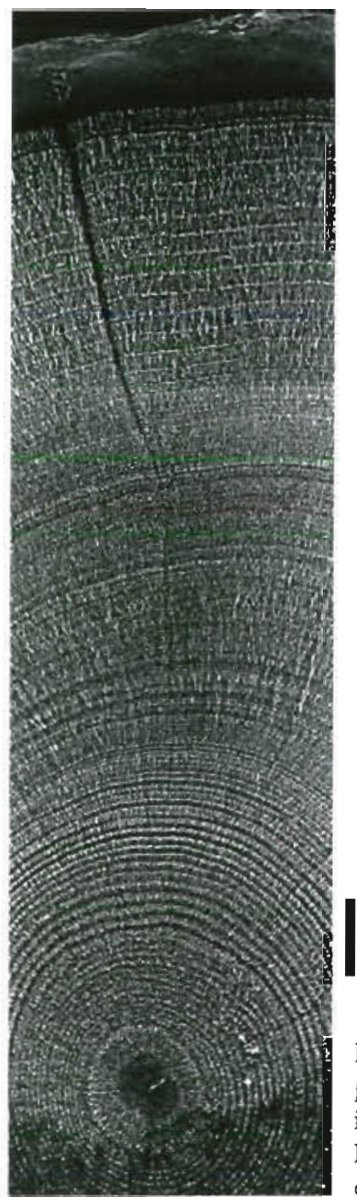

Fig. 3. Anguilla marmorata. SEM photograph showing otolith growth increments of a glass eel (total length $51.2 \mathrm{~mm}$ ) collected at mouth of Dumoga River. Scale bar $10 \mu \mathrm{m}$ 
observed around the core in each species (Fig. 3). Those otolith structures were similar to those reported in $A$ japonica (Tabeta et al. 1987, Tsukamoto 1990, Tzeng 1990, Umezawa \& Tsukamoto 1990, Tzeng \& Tsai 1992, Cheng \& Tzeng 1996), A. anguilla (Lecomte-Finiger 1992), A. marmorata (Budimawan 1997), A. rostrata (Wang \& Tzeng 1998) and A. bicolor pacifica (Arai et al. 1999).

A distinct check was observed some $15 \mu \mathrm{m}$ from the otolith edge in all otoliths of Anguilla celebesensis (mean $\pm \mathrm{SD}: 15.3 \pm 2.0 \mu \mathrm{m}$, range: 11.3 to $17.3 \mu \mathrm{m}$ ) and $A$. marmorata from the Philippines (mean $\pm \mathrm{SD}$ : $14.4 \pm 2.1 \mu \mathrm{m}$, range: 11.4 to $17.0 \mu \mathrm{m}$ ) (Fig. $2 \mathrm{~B}$ ), growth increments being unclear or irregular in the region outside the check. Campana \& Neilson (1985) suggested that the formation of such checks and discontinuities in otoliths appear during periods of perturbation and stress to the fish. The distinct check in all of the otoliths from the Philippines samples might have formed while the latter were maintained in freshwater after sampling. Therefore, growth increments outside the check were omitted from the age determination of Philippines samples, and the number of rings inside the check regarded as the age at recruitment. Such a check was not formed in otoliths of $A$. bicolor bicolor and $A$. marmorata from Indonesia (Fig. 2A).

\section{Age and hatching date}

Age at recruitment of Anguilla celebesensis, A. marmorata from the Philippines, A. marmorata from Indonesia and $A$. bicolor bicolor were $157 \pm 13.7 \mathrm{~d}$ (mean $\pm \mathrm{SD}), 154 \pm 13.5 \mathrm{~d}($ mean \pm SD), $152 \pm 15.2 \mathrm{~d}($ mean \pm SD) and $177 \pm 16.4 \mathrm{~d}$ (mean $\pm \mathrm{SD}$ ), respectively (Table 1 ). Significant differences occurred between $A$. marmorata from Indonesia and $A$. bicolor bicolor (ANOVA, $\mathrm{p}<0.001$ ), between $A$. bicolor bicolor and $A$. celebesensis (ANOVA, $p<0.05$ ), and between $A$. bicolor bicolor and $A$. marmorata from the Philippines (ANOVA, $p<0.005)$. No significant difference occurred between the 2 samples of $A$. marmorata (ANOVA, $p>0.1$ ).

The estimated hatch dates, back-calculated from the sampling date and ages, were from late March 1994 to mid-May 1994 for Anguilla celebesensis, from late March to early May 1994 for A. marmorata from the Philippines, from mid-December 1995 to late January 1996 for A. marmorata from Indonesia and from midNovember 1995 to early January 1996 for A. bicolor bicolor (Table 1). Significant differences occurred between $A$. celebesensis and $A$. marmorata from the Philippines (ANOVA, p $<0.0001$ ), between $A$. celebesensis and $A$. marmorata from Indonesia (ANOVA, $\mathrm{p}<0.0001$ ), between $A$. celebesensis and $A$. bicolor bicolor (ANOVA, $p<0.0001$ ), between the 2 samples of
A. marmorata (ANOVA, p $<0.0001$ ), between A. marmorata from the Philippines and $A$, bicolor bicolor (ANOVA, $\mathrm{p}<0.0001$ ) and between $A$. marmorata from Indonesia and $A$. bicolor bicolor (ANOVA, $\mathrm{p}<0.0001$ ). No significant difference was apparent between $A$. celebesensis and A. marmorata from the Philippines (ANOVA, $\mathrm{p}>0.1$ ).

\section{Otolith growth pattern}

Patterns of changing otolith increment widths along life-history transects from the core to the edge in each species are shown in Fig. 4. The common pattern observed in all specimens examined was divided into 4 phases, with drastic changes occurring in the latter 2 . A typical conceptual model for the changes in increment width is illustrated in Fig. 5. Otolith increment widths increased between the hatch check and age 20 to $40 \mathrm{~d}$ in each species (1st phase), thereafter becoming constant or gradually decreasing (average widths 0.38 to $0.44 \mu \mathrm{m}$ ) (2nd phase). Beyond age $124 \pm 12.0 \mathrm{~d}$ (mean $\pm \mathrm{SD}$ ) in Anguilla celebesensis, $120 \pm 13.0 \mathrm{~d}$ in A. marmorata from the Philippines, $120 \pm 15.6 \mathrm{~d}$ in A. marmorata from Indonesia and $139 \pm 15.9 \mathrm{~d}$ in A. bicolor bicolor, increment widths increased sharply to a maximum (average 2.51 to $2.76 \mu \mathrm{m}$ ) (3rd phase), followed by a rapid drop (4th phase). The latter ages differed significantly between $A$. celebesensis and A. bicolor bicolor (ANOVA, $\mathrm{p}<0.05$ ), between $A$. marmorata from Indonesia and $A$. bicolor bicolor (ANOVA, $\mathrm{p}<0.01$ ), and A. marmorata from the Philippines and $A$. bicolor bicolor (ANOVA, $p<0.01$ ). No significant difference was apparent between the 2 samples of A. marmorata (ANOVA, $p>0.1$ ). The mean duration of the $3 \mathrm{rd}$ phase, 17 to $18 \mathrm{~d}$ (Table 1), did not differ among the species (ANOVA, $p>0.1$ ).

\section{Otolith Sr:Ca ratios}

Otolith Sr:Ca ratios changed dramatically along the life-history transect in all species (Fig. 6), a typical conceptual model for the changes in Sr:Ca ratios is illustrated in Fig. 5. This pattern of microchemical changes was also commonly observed in the juveniles examined. Sr:Ca ratios, averaging 9.5 to $10.8 \times 10^{-3}$ at the core, dropped slightly at approximately the first phase of otolith growth. Subsequently, the ratios increased to a maximum level (average 13.2 to $16.3 \times 10^{-3}$ ) around the second phase and a markedly decreased thereafter toward the edge (coincident with the onset of the third phase of otolith growth). In Anguilla marmorata from Indonesia and $A$. bicolor bicolor, minimum values of 6.7 to $7.5 \times 10^{-3}$ were recorded in the 

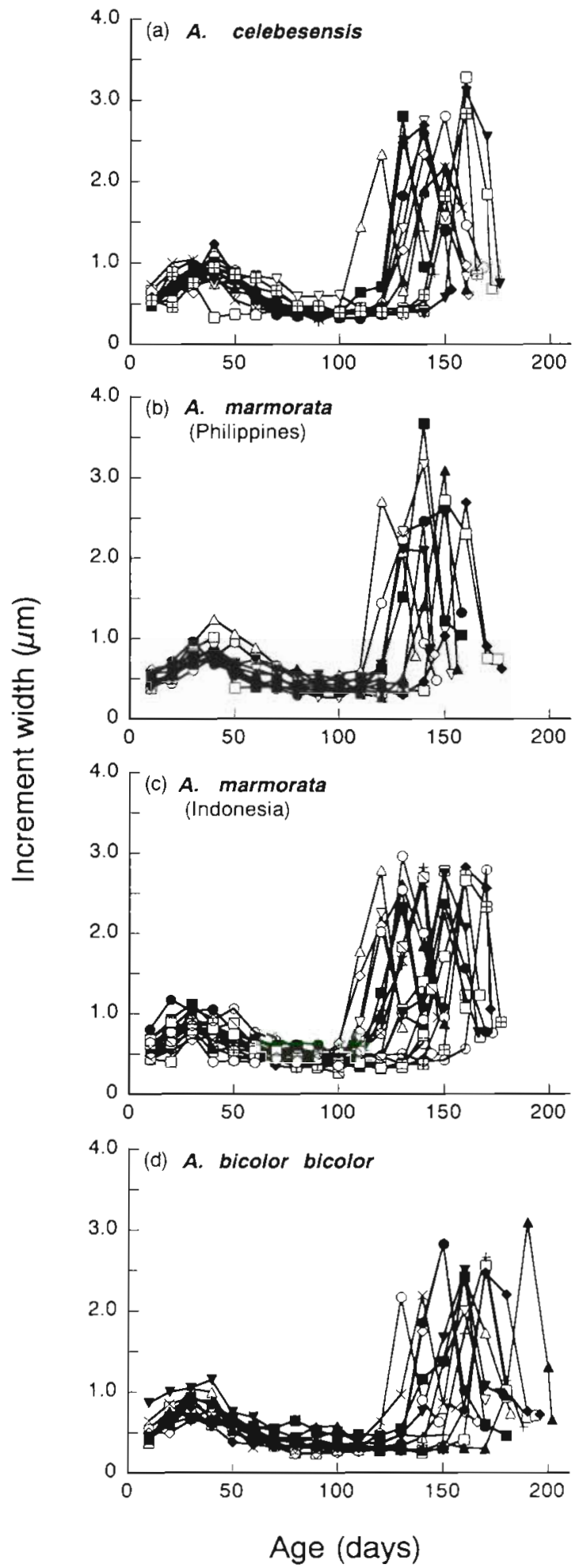

Fig. 4. Tropical Anquilla spp. Profiles of otolith incremental width from the core to the edge. Each point represents average of data for $10 \mathrm{~d}$. (a) A. celebesensis collected at mouth of Cagayan River, (b) A. marmorata collected at mouth of Cagayan River, (c) A. marmorata collected at mouth of Dumoga River, and (d) A. bicolor bicolor collected at mouth of Cimandiri River

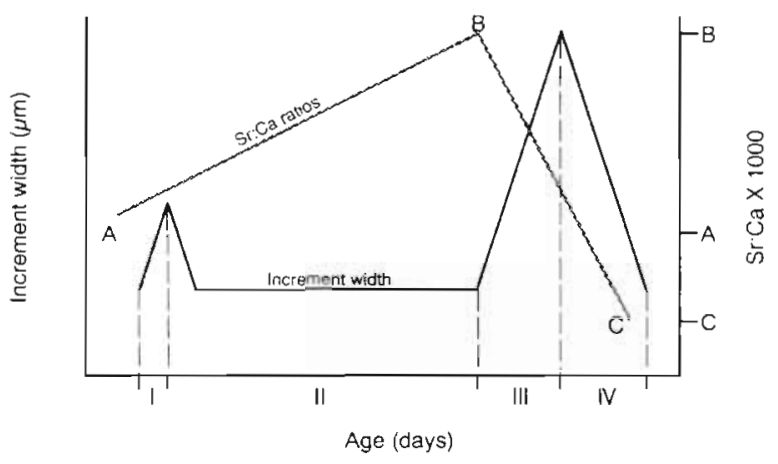

Fig. 5. Tropical Anguilla spp.. Conceptual model showing changes in otolith incremental widths and $\mathrm{Sr}$ : Ca ratios during the early life history of tropical Anguilla spp. I, II, III and IV indicate phases of width change; $A, B$ and $C$ indicate points of changing Sr:Ca ratios

outermost region of the otolith. In $A$. celebesensis and A. marmorata from the Philippines, values of 6.1 to $6.4 \times 10^{-3}$ were recorded in the outermost region at about $15 \mu \mathrm{m}$ inside the otolith edge. Furthermore, in $A$. celebesensis and A. marmorata from the Philippines, $\mathrm{Sr}: \mathrm{Ca}$ ratios in the region outside the distinct concentric check at about $15 \mu \mathrm{m}$ from the otolith edge (growth increment analysis omitted), decreased to even lower levels, averaging $3.4 \times 10^{-3}$ (range: 3.0 to $4.3 \times 10^{-3}$ ) in the former and $2.8 \times 10^{-3}$ (range: 2.6 to $3.0 \times 10^{-3}$ ) in the latter. The additional drop of otolith $\mathrm{Sr}$ :Ca ratios in the region outside the check may have resulted from the specimens being maintained in freshwater, as well as the formation of the distinct check in that region.

\section{Timing of metamorphosis}

Based on previous data on $\mathrm{Sr}$ :Ca ratios in Anguilla japonica and A bicolor pacifica (Otake et al. 1994, Arai et al. 1997, 1999), age at Point B (Fig. 5) where Sr:Ca ratios showed a drastic decrease was regarded as the onset of metamorphosis in each species examined here. Close linear relationships were apparent between age at metamorphosis and age at recruitment in all groups (Fisher's Z-transformation, $\mathrm{p}<0.0005$ ). No significant difference in regression slopes occurred between the 2 A. marmorata samples (ANCOVA, $p>0.1$ ) (Fig. 7).

\section{DISCUSSION}

\section{Metamorphosis}

All otoliths of the juveniles examined in the present study displayed a similar growth pattern which was divided into 4 phases (Fig. 6), the last 2 phases over- 
Fig. 6. Tropical Anguilla spp.. Profiles of otolith incremental width from the core to the edge (o) and otolith Sr:Ca concentration ratios measured with a wavelength dispersive electron microprobe from the core to the edge $(\Delta)$. Each point represents average of data for $10 \mathrm{~d}$. Numbers in bold in upper right-hand corner suggest age (d). Profiles of specimens of least (top rows), average (middle rows) and greatest age (bottom rows) of each species. (a) A, celebesensis collected at mouth of Cagayan River, (b) A. marmorata collected in the mouth of Cagayan River, (c) A. marmorata collected at mouth of Dumoga River, and (d) A. bicolor bicolor collected at mouth of Cimandiri River
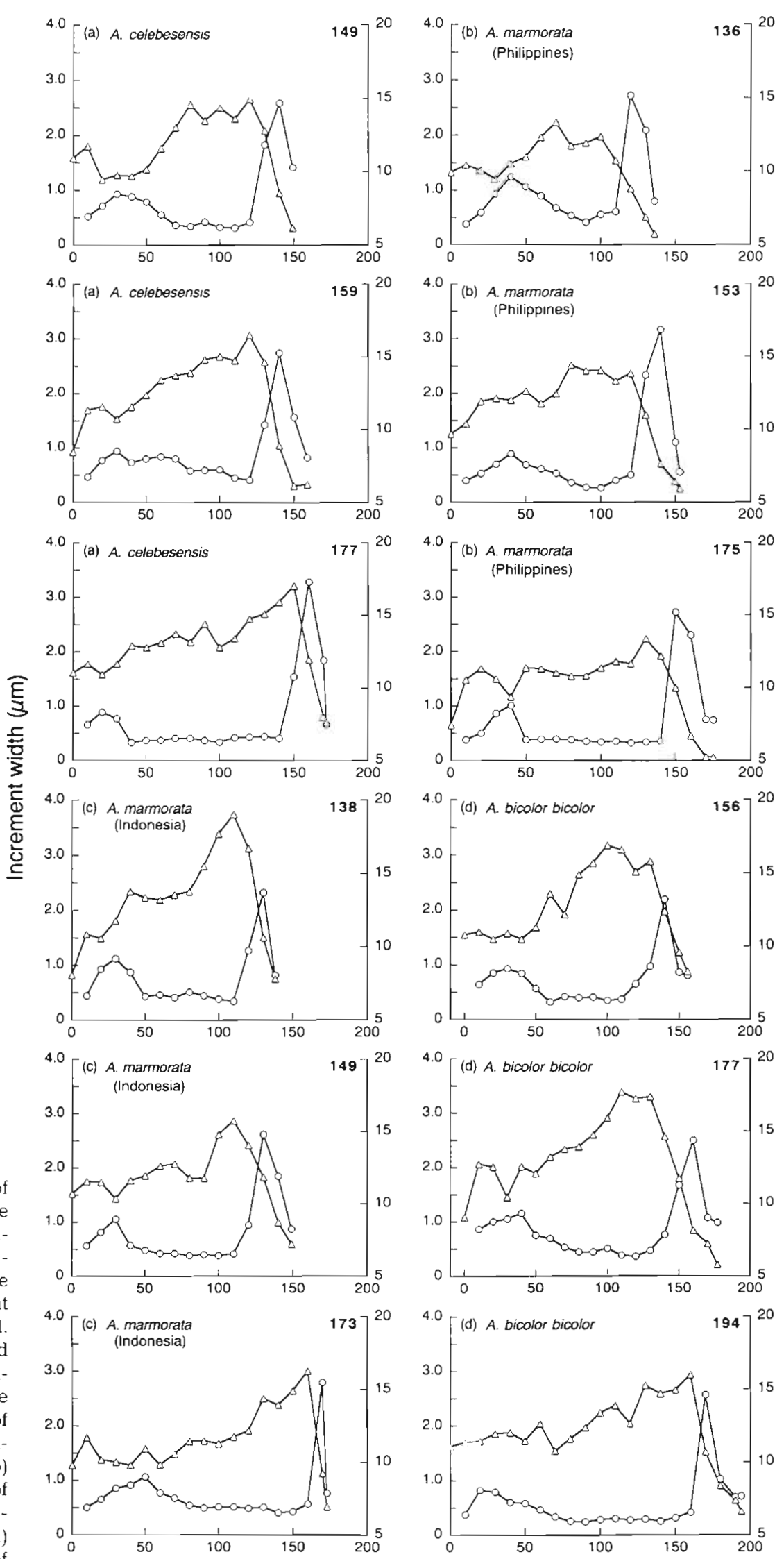

Age (days)

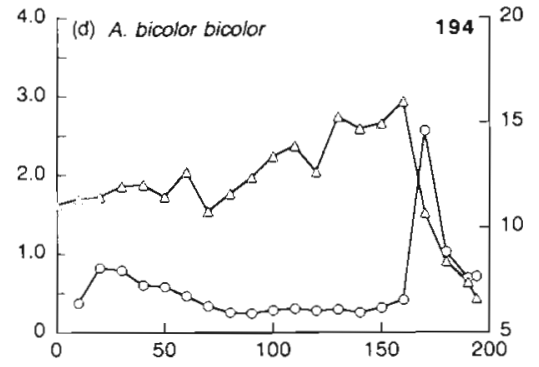

Age (days) 


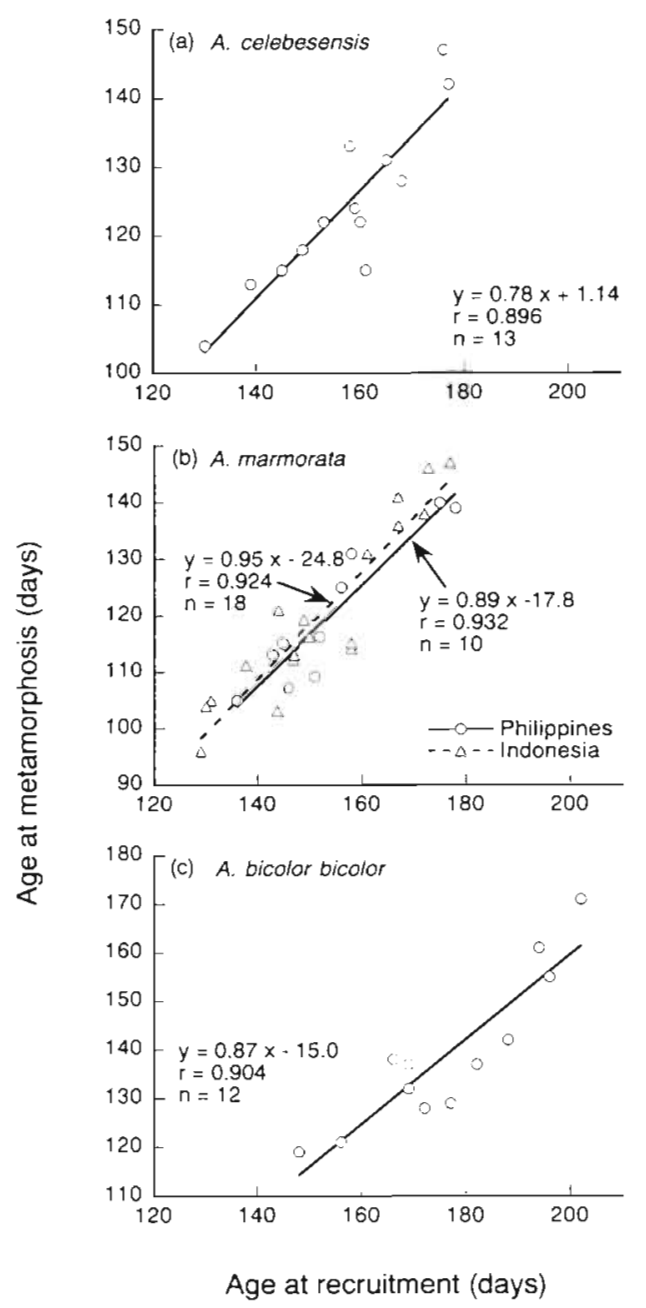

Fig. 7 Tropical Anguilla spp. Relationship between age at recruitment and age at metamorphosis. (a) A celebesensis collected at mouth of Cagayan River, (b) A. marmorata collected at mouth of Cagayan River and Dumoga River, and (c) A bicolor bicolor collected at mouth of Cimandiri River

lapping exactly with a drop in otolith $\mathrm{Sr}$ :Ca ratios. Such a fluctuation pattern, associated with the Sr:Ca ratios, appeared to be quite similar to those in Anguilla japonica (Otake et al. 1994, Arai et al. 1997) and A. bicolor pacifica (Arai et al. 1999). Otake et al. (1997) found a similar phenomenon in Conger myriaster. The coincidence in timing of the rapid increase in increment width and sharp decrease in Sr:Ca ratios in the otolith seems to be a common pattern in anguillid fishes. A comparison of microstructure and microchemistry analyses in fully grown leptocephali and glass eels led to the conclusion that the timing of the rapid increase in otolith increment widths and sharp decrease in $\mathrm{Sr}$ : Ca ratios heralded the onset of metamorphosis in $A$. japonica (Arai et al. 1997). Therefore, early life-history transects of otoliths of the tropical Anguilla species can be interpreted as follows: Phases I and II--preleptocephalus and leptocephalus, Phase III-metamorphosis and Phase IV-glass eel. Accordingly, the onset of metamorphosis in $A$. celebesensis, $A$. marmorata from the Philippines, A. marmorata from Indonesia and $A$. bicolor bicolor seemed to occur at mean ages of $124 \mathrm{~d}$ $( \pm 12.0 \mathrm{~d}$ SD $), 120 \mathrm{~d}( \pm 13.0 \mathrm{~d}$ SD $), 120 \mathrm{~d}( \pm 15.6 \mathrm{~d} \mathrm{SD})$ and $139 \mathrm{~d}( \pm 15.9 \mathrm{~d}$ SD), respectively. Arai et al. (1997. 1999) suggested that metamorphosis is completed before the maximum peak of otolith increment width, because the increment width did not decrease following its maximum level in several specimens recruited to a coast. Therefore, the maximum duration of metamorphosis is likely to be at most 17 or $18 \mathrm{~d}$ for each species. It is noteworthy that the duration of the metamorphosis stage is constant, even in different species.

\section{Recruitment to freshwater}

The relationship between the timing of metamorphosis and age at recruitment clearly showed that juveniles undergoing the former at an earlier age tended also to migrate to a coastal region at a younger age, indicating that early metamorphosing larvae are recruited earlier (Fig. 7). Tsukamoto \& Umezawa (1994) and Arai et al. $(1997,1999)$ found the same phenomenon in Anguilla japonica and A. bicolor pacifica, respectively.

In the present study, the mean duration of the leptocephalus stage across the species ranged from 120 to $139 \mathrm{~d}$, the ages at recruitment being determined as averaging between 152 and $177 \mathrm{~d}$ (Table 1). The early life history parameters were almost the same between the 2 groups of Anguilla marmorata, the duration of the leptocephalus stage in both being $120 \mathrm{~d}$ and the ages at recruitment $154 \mathrm{~d}$ (Philippines) and $152 \mathrm{~d}$ (Indonesia). Similar results have also been found between subspecies of $A$, bicolor, $A$. bicolor bicolor beginning to metamorphosis at $139 \mathrm{~d}$ and undergoing recruitment to western Java Island at $177 \mathrm{~d}$ (present study), and $A$. bicolor pacifica from the mouth of Dumoga River, Indonesia, metamorphosing at $135 \mathrm{~d}$ and being recruited at $173 \mathrm{~d}$ (Arai et al. 1999). These results suggested that early life history parameters such as duration of the leptocephalus stages and ages at recruitment were almost equal in $A$. marmorata and $A$. bicolor, in spite of their different geographical distribution, ocean migration routes and growth histories. Furthermore, the early life history parameters found in all tropical species overlapped with the range of those in the temperate species $A$. japonica although the former were a little shorter than those of $A$. anguilla and A. rostrata (Table 2).

The estimated hatching periods of Anguilla marmorata collected in the Philippines and Indonesia 
Table 2. Anguilla spp. DL: duration of leptocephalus stage, and AR: age at recruitment reported in literature for otolith SEM studies of various Anguilla species

\begin{tabular}{|lrrl|}
\hline Species & DL (d) & AR (d) & \multicolumn{1}{c|}{ Source } \\
\hline $\begin{array}{l}\text { Temperate species } \\
\text { A. japonica }\end{array}$ & 110 to 140 & 120 to 173 & Tabeta et al. (1987) \\
& & 113 to 157 & Tzeng (1990) \\
& 116 to 138 & 155 to 182 & Cheng and Tzeng (1996) \\
A. anguilla & 80 to 160 & 143 to 206 & Arai et al. (1997) \\
A. rostrata & 176 to 196 & 216 to 276 & Lecomte-Finiger (1992) \\
& 189 to 214 & 220 to 284 & Wang \& Tzeng (1998) \\
Tropical species & & & \\
A. marmorata & & & \\
& 81 to 86 & 96 to 131 & Budimawan (1997) \\
& 105 to 140 & 136 to 178 & Present study (Philippines) \\
A. bicolor pacifica & 101 to 147 & 129 to 177 & Present study (Indonesia) \\
A. bicolor bicolor & 119 to 171 & 148 to 202 & Arai et al. (1999) \\
A. celebesensis & 104 to 147 & 130 to 177 & Present study \\
\cline { 4 - 5 } & & & Present study \\
\hline
\end{tabular}

small sizes in tropical eel juveniles (47.0 to $51.8 \mathrm{~mm}$ in $A$. marmorata and $48.9 \mathrm{~mm}$ in A. bicolor pacifica), similar to those species used in the present study, when they arrived at river mouths in tropical areas. Furthermore, differences in the total lengths of fully grown leptocephali were also found between tropical and temperate species. The TLs of fully grown leptocephali of the temperate eels, $A$. anguilla, A. rostrata and A. japonica, were estimated as $75 \mathrm{~mm}$ (Jespersen 1942, Tesch 1977), $70 \mathrm{~mm}$ (Kleckner \& McCleave 1985) and $60 \mathrm{~mm}$ (Tabeta \& Konishi 1986), respectively, while those of tropical species collected in the Indo-pacific region including $A$. celebesensis, A. marmorata and $A$. bicolor bicolor, have been reported as being around $50 \mathrm{~mm}$ (Jespersen 1942).

differed from each other by 2 mo. The recruitment sites were different, as were the ocean current systems around each area. However, the age at recruitment was almost equal at the different sites, suggesting the existence of at least 2 reproductively isolated populations of $A$. marmorata in the Indo-Pacific region. Nevertheless, not all of the recruitment period was covered. In order to discriminate between populations of A. marmorata, time series samples need to be examined or a molecular analysis of the species undertaken.

\section{Size at recruitment and early growth}

Conspicuous early life history discrepancies between the tropical and temperate species were apparent in the total lengths of juveniles. The TLs of Anguilla marmorata from Indonesia and $A$. bicolor bicolor at recruitment $(50.9 \pm 2.0 \mathrm{~mm}$ in the former, $49.4 \pm 2.4 \mathrm{~mm}$ in the latter; mean $\pm \mathrm{SD}$ ) were 10 to $20 \mathrm{~mm}$ less than those of temperate Anguilla species, such as $A$. anguilla (68 mm) (Lecomte-Finiger 1992) and A. japonica (57 mm) (Umezawa 1991, Cheng \& Tzeng 1996, Arai et al. 1997), even though all 4 species conform to the same pigmentation stage, i.e. stage VA or VB. Similarly, juvenile TLs at recruitment of $A$. celebesensis (51.2 $\pm 1.7 \mathrm{~mm}_{i}$ mean $\left.\pm \mathrm{SD}\right)$ and $A$. marmorata $(49.9 \pm 1.4 \mathrm{~mm}$; mean $\pm \mathrm{SD})$ from the Philippines were 10 to $20 \mathrm{~mm}$ less than those of temperate Anguilla species, such as $A$. australis (59 to $73 \mathrm{~mm}$ ) (Jellyman 1979). A. rostrata (55.8 to $60.9 \mathrm{~mm}$ ) (Haro \& Krueger 1988 ) and $A$. anguilla (65 mm) (Lecomte-Finiger 1992). Budimawan (1997) and Arai et al. (1999) also reported
According to our age determinations, the growth rates of leptocephali of the latter 3 species were estimated to range from 0.36 to $0.42 \mathrm{~mm} \mathrm{~d}^{-1}$, that is, less than those reported for the temperate eel, $A$. japonica $(0.56$ to $0.59 \mathrm{~mm} \mathrm{~d}^{-1}$ ) (Umezawa \& Tsukamoto 1990, Tsukamoto et al. 1992), which has a similar length larval phase. The lower growth rate during the leptocephalus stage of tropical eels, including $A$. celebesensis, $A$. marmorata and $A$. bicolor bicolor, seems to result in the smaller size of the fully grown leptocephali and smaller size at recruitment in those species.

\section{Ocean migration and distribution}

Anguilla celebesensis, A. marmorata and A. bicolor bicolor leptocephali were determined as taking about 5 to 6 mo to migrate from their spawning area to estuarine habitats, and $A$. bicolor pacifica requiring a similar period, according to a previous study (Arai et al. 1999). In temperate eels, which migrate via oceanic current systems (Schmidt 1922, 1925, Tsukamoto 1992), the duration of oceanic migration seems to be related to the distance and complexity of the current systems between the spawning areas and the freshwater habitat destinations. According to Jespersen (1942), spawning areas of tropical eels, including $A$. bicolor bicolor and $A$. marmorata from Indonesia, distributed off Java and the North Sulawesi Islands, respectively, are possibly situated off the southwestern coast of Sumatra for the former and the Celebes, Sulu and Molucca Seas for the latter, i.e. close to their distribution area (Fig. 1). Therefore, the rather long migration periods of those species relative to the short distances 
between their growth habitat and spawning area may be due to complicated local current systems around Sumatra and Java, and the North Sulawesi Islands. The occurrence of leptocephali of various sizes, including preleptocephalus to metamorphosing stages, in waters off Sumatra (Jespersen 1942) support that supposition. This situation is quite different to that of temperate eels, suggesting that the migration mechanisms of tropical eel larvae are not as simple as those of temperate eels, which can be interpreted as simple transportation by steady currents. These considerations suggest that primitive eels would initiate diadromous migration from a local short-distance movement in complex currents in tropical coastal waters rather than from a long-distance migration of temperate eels well established in subtropical gyres in both hemispheres.

Acknowledgements. We are grateful to Dr G. S. Hardy, Thames, New Zealand, for his critical reading of the manuscript, and also thank to Mr. Irianto for assistance in collecting samples in Indonesia. This work was supported in part by Grants-in-Aid No.s 07306022, 07556046, 08041139 and 08456094 from the Ministry of Education, Science, Sports and Culture, Japan; Research for the Future Program No. JSPSRFTF 97 L00901 from the Japan Society for the Promotion of Science $_{i}$ Eel Research Foundation from Nobori-kai; Research Foundation from Touwa Shokuhin Shinkoukai. Partial support was also given in the form of a Research Fellowship of the Japan Society for the Promotion of Science for Young Scientists to T.A.

\section{LITERATURE CITED}

Aoyama J (1998) Molecular phylogeny and evolution of the freshwater eels, genus Anguilla. PhD thesis, The University of Tokyo

Arai T, Tsukamoto K (1998) Application of otolith Sr:Ca ratios to estimate the migratory history of masu salmon, Oncorhynchus masou. Ichthyol Res 45:309-313

Arai T, Otake T, Tsukamoto K (1997) Drastic changes in otolith microstructure and microchemistry accompanying the onset of metamorphosis in the Japanese eel Anguilla japonica. Mar Ecol Prog Ser 161:17-22

Arai T, Otake T, Daniel L, Tsukamoto K (1999) Early life history and recruitment of the tropical eel, Anguilla bicolor pacifica, as revealed by otolith microstructure and microchemistry. Mar Biol 133:319-326

Bertin L (1956) Eels - a biological study. Cleaver-Hume Press Ltd, London

Budimawan (1997) The early life history of the tropical eel Anguilla marmorata (Quoy \& Gaimard, 1824) from four Pacific estuaries, as revealed from otolith microstructural analysis. J Appl Ichthyol 13:57-62

Campana SE, Neilson JD (1985) Microstructure of fish otoliths. Can J Fish Aquat Sci 42:1014-1032

Castle PHJ, Williamson GR (1974) On the validity of the freshwater eel species Anguilla ancestralis Ege from Celebes. Copeia 2:569-570

Cheng PW, Tzeng WN (1996) Timing of metamorphosis and estuarine arrival across the dispersal range of the Japanese eel Anguilla japonica. Mar Ecol Prog Ser 131:87-96
Ege V (1939) A revision of the Genus Anguilla Shaw. DanaRep Carlsberg Foundation 16(13):8-256

Haro AJ, Krueger HW (1988) Pigmentation, size, and migration of elvers (Anguilla rostrata (Lesueur)) in a coastal Rhode Isiand stream. Can J Zool 66:2528-2533

Jellyman DJ (1979) Upstream migration of glass-eels (Anguilla spp.) in the Waikato River. NZ J Mar Freshw Res 13: $13-22$

Jespersen P (1942) Indo-Pacific leptocephali of the Genus Anguilla. Dana-Rep Carlsberg Foundation 22:1-128

Kleckner RC, McCleave JD (1985) Spatial and temporal distribution of American eel larvae in relation to North Atlantic Ocean current systems. Dana 4:67-92

Lecomte-Finiger R (1992) Growth history and age at recruitment of European glass eels (Anguilla anguilla) as revealed by otolith microstructure. Mar Biol 114:205-210

Matsui I (1972) Eel biology-biological study. KoseishaKoseikaku, Tokyo

Otake T, Ishij T, Nakahara M, Nakamura R (1994) Drastic changes in otolith strontium/calcium ratios in leptocephali and glass eels of Japanese eel Anguilla japonica. Mar Ecol Prog Ser 112:189-193

Otake $T$, Ishii $T$, Ishii $T$, Nakahara M, Nakamura R (1997) Changes in otolith strontium:calcium ratios in metamorphosing Conger myriaster leptocephali. Mar Biol 128: $565-575$

Schmidt J (1922) The breeding places of the eel. Phil Trans R Soc (Ser B) 211:178-208

Schmidt J (1925) The breeding places of the eel. Annu Rep Smithson Inst 1924:279-316

Sokal RR, Rohlf FJ (1969) Biometry. WH Freeman and Co, San Francisco

Tabeta O, Konishi Y (1986) An anguillid leptocephalus Anguilla japonica from the waters of Miyako Island, Okinawa, Japan. Bull Jap Soc Scient Fish 52:1935-1937

Tabeta O. Takai T, Matsui I (1976) The sectional counts of vertebrae in the anguillid elvers. Jap J Ichthyol 22:195-200

Tabeta O, Tanaka K, Yamada J, Tzeng WN (1987) Aspects of the early life history of the Japanese eel Anguilla japonica determined from otolith microstructure. Bull Jap Soc Scient Fish 53:1727-1734

Tesch FW (1977) The eel. Biology and management of anguillid eels. Chapman and Hall, London

Tsukamoto K (1989) Otolith daily growth increments in the Japanese eel. Bull Jap Soc Scient Fish 55:1017-1021

Tsukamoto $K$ (1990) Recruitment mechanism of the eel, Anguilla japonica, to the Japanese coast. J Fish Biol 36: $659-671$

Tsukamoto K (1992) Discovery of the spawning area for the Japanese eel. Nature 356:789-791

Tsukamoto K (1994) Freshwater fishes migrating between river and the sea. Tokai University Press, Tokyo

Tsukamoto K, Aoyama J (1998) Evolution of freshwater eels of the genus Anguilla: a probable scenario. Environ Biol Fishes 52 139-148

Tsukamoto K, Umezawa A (1990) Early life history and oceanic migration of the eel, Anguilla japonica. La Mer 28:188-198

Tsukamoto K, Umezawa A. (1994) Proceedings of the fourth Indo-Pacific fish conference. Bangkok, p 231-248

Tsukamoto K, Umezawa A, Ozawa T (1992) Age and growth of Anguilla japonica leptocephali collected in Western North Pacific in July 1990. Bull Jap Soc Scient Fish 58: $457-459$

Tzeng WN (1990) Relationship between growth rate and age at recruitment of Anguilla japonica elvers in a Taiwan estuary as inferred otolith growth increments. Mar Biol $107: 75-81$ 
Tzeng WN (1994) Temperature effects on the incorporation of strontium in otolith of Japanese eel Anguilla japonica. J Fish Biol 45:1055-1066

Tzeng WN (1996) Effects of salinity and ontogenetic movements on strontium:calcium ratios in the otoliths of the Japanese eel, Anguilla japonica Temminck and Schlegel. J Exp Mar Biol Ecol 199:111-122

Tzeng WN, Tsai YC (1992) Otolith microstructure and daily age of the Anguilla japonica, Temminck and Schlegel elvers from the estuaries of Taiwan with reference to unit stock and larval migration. J Fish Biol 40:845-857

Tzeng WN, Tsai YC (1994) Changes in otolith microchemistry of the Japanese eel, Anguilla japonica, during its migration from the ocean to the rivers of Taiwan. J Fish Biol 45:671-683

Umezawa A. (1991) Early life history and recruitment mecha-

Editorial responsibility: Otto Kinne (Editor),

Oldendorf/Luhe, Germany nism of the eel, Anguilla japonica. PhD thesis, The University of Tokyo

Umezawa A, Tsukamoto K (1990) Age and birth date of the glass eel, Anguilla japonica, collected in Taiwan. Bull Jap Soc Scient Fish 56:1199-1202

Umezawa A, Tsukamoto K (1991) Factors influencing otolith increment formation in Japanese eel, Anguilla japonica $\mathrm{T}$ and S., elvers. J Fish Biol 39:211-223

Umezawa A, Tsukamoto K, Tabeta O, Yamakawa H (1989) Daily growth increments in the larval otolith of the Japanese eel, Anguilla japonica. Jap J Ichthyol 35:440-444

Wang $\mathrm{CH}$, Tzeng WN (1998) Interpretation of geographic variation in size of American eel Anguilla rostrata elvers on the Atlantic coast of North America using their life history and otolith ageing. Mar Ecol Prog Ser 168:35-43

Submitted: December 8, 1998; Accepted: March 16, 1999 Proofs received from author(s): May 31, 1999 